\title{
EFFECT OF MECHANICAL AND PHYSICAL PROPERTIES OF ALUMINUM ALLOY LM12 WITH THE REINFORCEMENT OF SILICON CARBIDE
}

\author{
Suresha $\mathbf{P}$ \\ South East Asian College of Engineering and Technology, Bangalore, India \\ Chikkanna N \\ Visvesvaraya Institute of Advanced Technologies, VTU, Muddenahalli, India \\ Iranna M Biradar \\ BAZE University Abuja, Nigeria
}

\begin{abstract}
Aluminum alloy LM12 metal matrix composites are broadly used in different industrial application, because it having greater mechanical and chemical properties. This paper contains around the change in mechanical properties of AL LM-12 when it is reinforced with $\mathrm{SiC}$ of production by using stir casting techniques. For this reason AL LM-12 and reinforcement of SiC with various wt\% utilized. SiC is reinforced in 0 , 5, 10, 15 and $20 w t \%$. Impact of SiC reinforcement on AL LM-12 and its properties are $B H N$ and microstructure analysis of MMC's discussed in detail of this paper.
\end{abstract}

Key words: AL/SiC, AL LM-12 MMC's and BHN and microstructure analysis

Cite this Article: Suresha P, Chikkanna N and Iranna M Biradar, Effect of Mechanical and Physical Properties of Aluminum Alloy LM12 with the Reinforcement of Silicon Carbide, International Journal of Production Technology and Management (IJPTM), 10(1), 2019, pp. 1-8.

http://iaeme.com/Home/issue/IJPTM?Volume=10\&Issue $=1$

\section{INTRODUCTION}

Metal matrix composites are obtained by reinforcement of ceramic particles to a base metal to realize improvements in properties (1-5). The reinforcements forms can be found in fibers, whiskers and particulates(6-8). To achieve the required properties of MMC-reinforcement material, fabrication method, varying percent and \%wt can be followed to make it suitable of industrial applications. Because of their superior strength, less weight ratio and hardness of metal matrix composites are replacing monolithic materials in aerospace as well as automobile industries. (9-13). 
Present work describes the hardness and microstructural analysis of LM12 Aluminum alloy with reinforcement of silicon carbide with various \%wt of $\mathrm{SiC}$.

Table: 1 composition of the LM12 alloy

\begin{tabular}{|c|c|c|c|}
\hline Element & Wt.\% & Element & Wt\% \\
\hline Copper & $09-11$ & Zinc & $0.8 \mathrm{max}$ \\
\hline Magnesium & $0.2-0.4$ & Lead & $0.1 \mathrm{max}$ \\
\hline Silicon & $2.5 \mathrm{max}$ & Tin & $0.05 \mathrm{max}$ \\
\hline Iron & $1.0 \mathrm{max}$ & Titanium & $0.2 \mathrm{max}$ \\
\hline Manganese & $0.6 \mathrm{max}$ & aluminum & Balance \\
\hline Nickel & $0.5 \mathrm{max}$ & & \\
\hline
\end{tabular}

\section{EXPERIMENTAL SET UP}

As we know wear is process of removal of material eviction that usually occurs at outer surface of the material. In this experiment totally five specimens are prepared, having same length and diameter but different wt \% of $\mathrm{SiC}(\%$ wt $0,5,10,15 \& 20)$ MMC's. Conducted the BHN and analysis of microstructure of MMC's

\subsection{Development of MMC's by using stir casting process}

The specimens are produced by using a stir casting process as shown in Fig.1

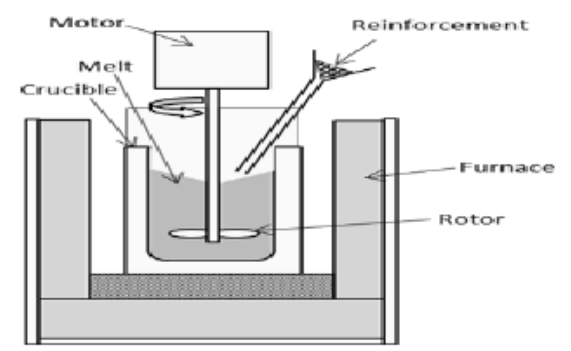

Figure 1 Stir casting process

\section{RESULTS AND DISCUSSION}

\subsection{Brinells hardness test (BHN)}

Hardness testing machine, Brinell's micrometer, specimen, ball indentor of $5 \mathrm{~mm}$.

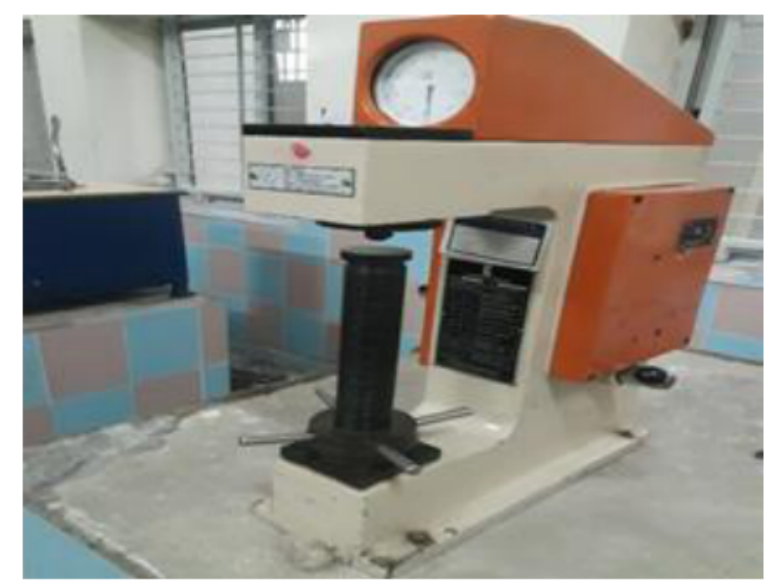

Figure 2 Hardness testing machine 
Effect of Mechanical and Physical Properties of Aluminum Alloy LM12 with the Reinforcement of Silicon Carbide

Table 2 Brinells hardness test

\begin{tabular}{|c|c|}
\hline Specifications & Ranges \\
\hline Maximum test height & $225 \mathrm{~mm}$ \\
\hline Depth of thread & $130 \mathrm{~mm}$ \\
\hline $\begin{array}{c}\text { Max depth of screw } \\
\text { below base }\end{array}$ & $260 \mathrm{~mm}$ \\
\hline Max load & $250 \mathrm{kgf}$ \\
\hline Net weight & $65 \mathrm{kgf}$ \\
\hline
\end{tabular}

$$
\text { B.H.N }=\frac{2 P}{\pi D\left(D-\sqrt{\left(D^{2}\right.}-d^{2}\right)}
$$

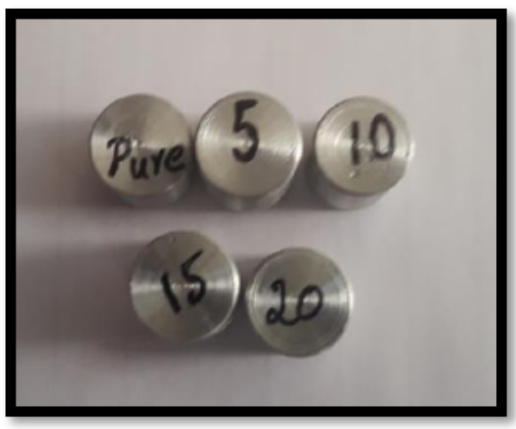

Figure 3 Weight

\subsection{Parameters}

Table 3 Parameters

\begin{tabular}{|c|c|c|}
\hline Ball material & Hardened steel & constant \\
\hline $\begin{array}{c}\text { Specimen } \\
\text { material }\end{array}$ & $\begin{array}{c}\text { AL alloy } \\
\text { LM12/SiC }\end{array}$ & \\
\hline Specimen & 12 & $\begin{array}{c}\text { ISO6506- } \\
\text { dimension }\end{array}$ \\
\hline Ball dia(mm) & 5 & constant \\
\hline Load $(\mathrm{kgf})$ & 250 & constant \\
\hline Test time $(\mathrm{Sec})$ & 20 & constant \\
\hline
\end{tabular}

\subsection{Specimen Calculations}

$$
\begin{aligned}
& \text { B.H.N }=\frac{2 P}{\pi D\left(D-\sqrt{\left(D^{2}\right.}-d^{2}\right)} \\
& \text { B.H.N }=\frac{2(250)}{\pi 5\left(5-\sqrt{\left(5^{2}\right.}-2.5^{2}\right)} \\
& \text { B.H.N }=47.5 \mathrm{Kgf} / \mathrm{mm}^{2}
\end{aligned}
$$


Table 4 Specimen

\begin{tabular}{|c|c|c|}
\hline Test Material & $\begin{array}{c}\text { Diameter of } \\
\text { indentation } \\
\mathbf{d}(\mathbf{m m})\end{array}$ & B.H.N \\
\hline LM 12 & 2.5 & 47.5 \\
\hline LM 12+5\% SIC & 2.3 & 56.8 \\
\hline LM 12+10\%SIC & 2.2 & 62.4 \\
\hline LM 12+15\%SIC & 2.1 & 68.8 \\
\hline LM12+20\% SIC & 1.9 & 84.8 \\
\hline
\end{tabular}

Conducted the BHN test under specifications which is shown in table 2 and 3 The MMC's of aluminum alloy LM12.The reinforcement of $\mathrm{SiC}$ at Different wt.\% $\mathrm{SiC}$ various in the ranges 0,5,10,15,20 wt.\% Al alloy LM12 (MMC's) shown in fig:4. Improvement results shown in below graph fig:3.3.

\subsection{Graphs BHN v/s Different MMC's Compositions}

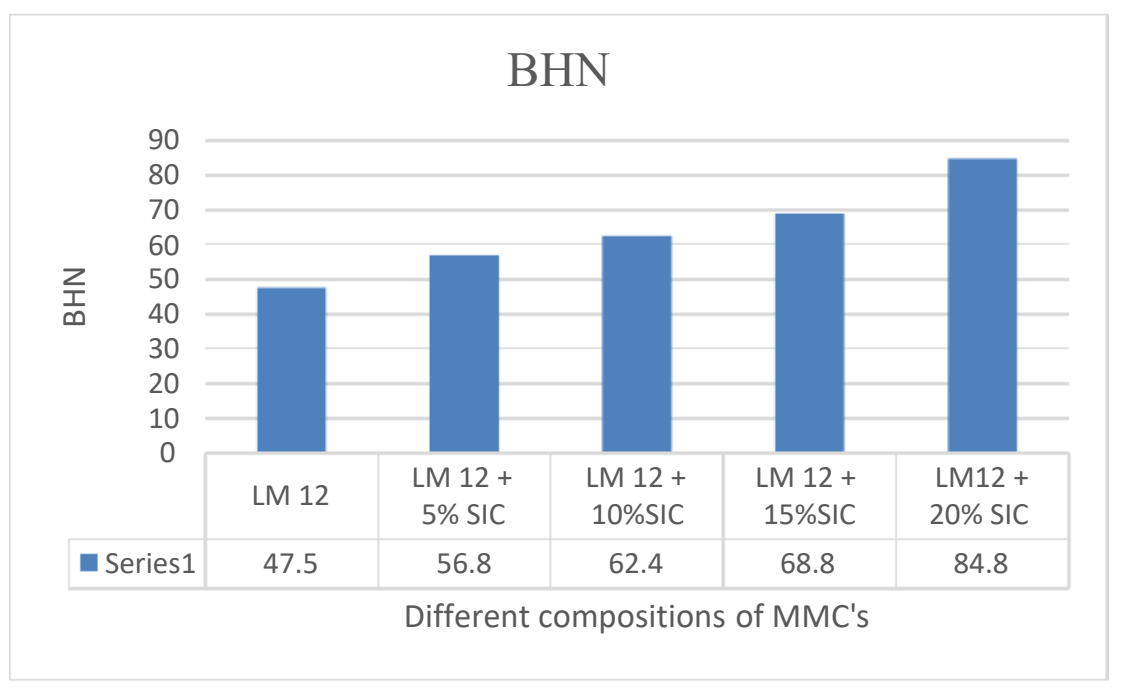

Figure 4 BHN

Shown the above fig no: $4 \mathrm{X}$-axis plotted against the MMC's, whereas Y-axis represents value $\mathrm{BHN}$.

Table 4 depicts an increase in hardness of the composite with enhanced SiC content. Enhancement in hardness of about $19 \%$ for $5 \% \mathrm{SiC}, 32 \%$ for $10 \% \mathrm{SiC}, 45 \%$ for $15 \% \mathrm{SiC}$ and $78 \%$ for $20 \% \mathrm{SiC}$ over and above that in the base metal was realized. Enhanced hardness could be attributed to dispersion hardening due to reinforcements in the matrix. Dispersion hardening has been attributed to reduced mobility of dislocations pinned down by dispersoids in the matrix.

\section{METALLOGRAPHY (MICROSTRUCTURE)}

The microstructure analysis of MMC's of aluminum alloy LM12. With the reinforcement of SiC. Different wt.\% various at 0,5,10,15,20 wt.\% of SiC and Optical Metallurgical Microscope obtained from NIKON Epiphot 200 machine as used. As shown in below picture. 
Effect of Mechanical and Physical Properties of Aluminum Alloy LM12 with the Reinforcement of Silicon Carbide

\subsection{Microstructure analysis of Aluminum alloy of LM12}

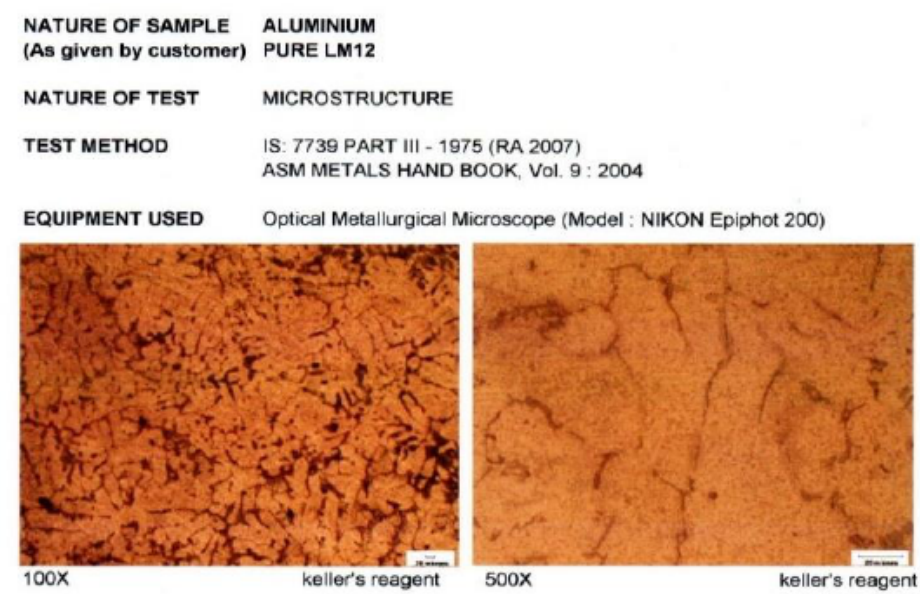

Figure 5 Microstructure analysis of LM12

\subsection{Microstructure analysis of Aluminum alloy of $\mathrm{LM} 12+5 \% \mathrm{SiC}$}

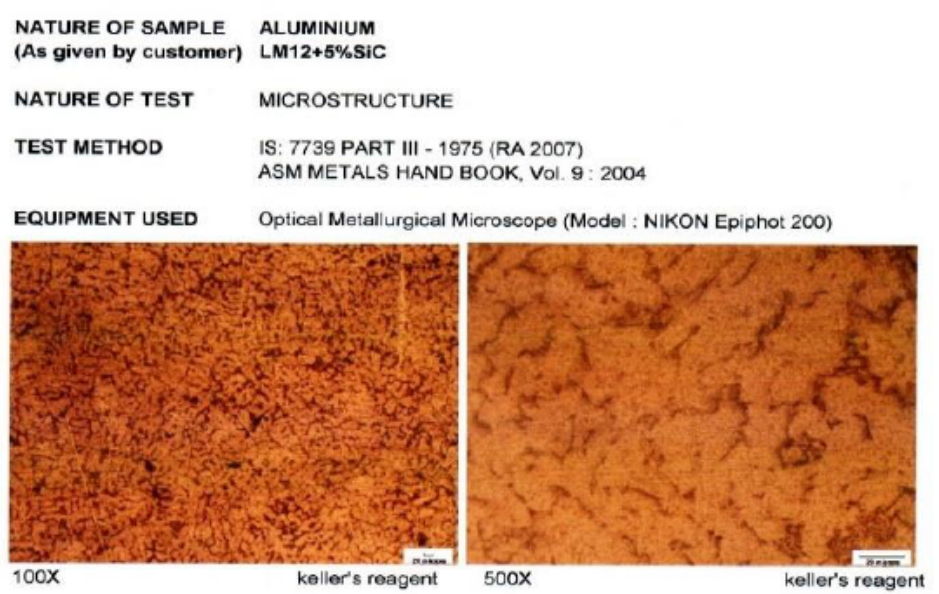

Figure 5 Microstructure analysis of $\mathrm{LM} 12+5 \% \mathrm{SiC}$

\subsection{Microstructure analysis of Aluminum alloy of $\mathrm{LM} 12+10 \% \mathrm{SiC}$}

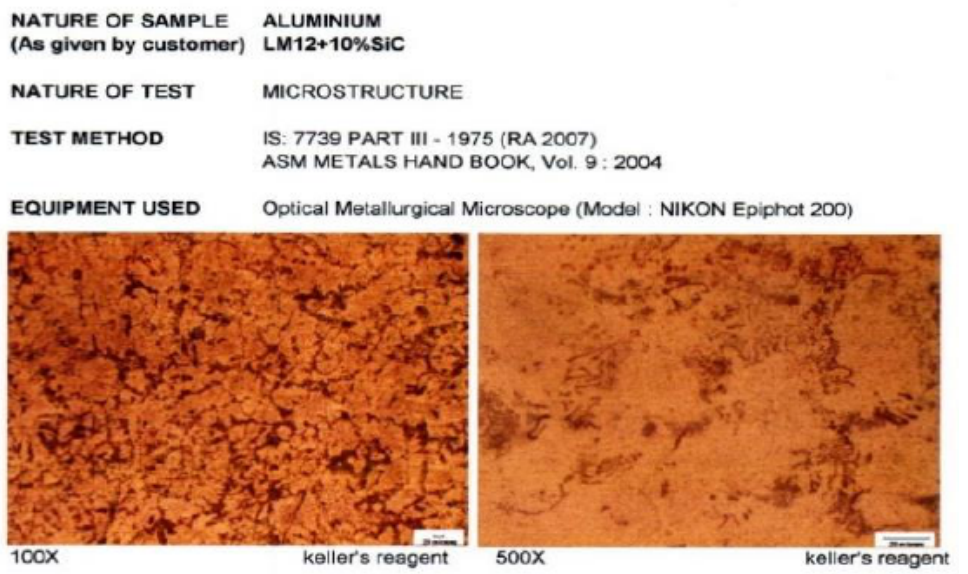

Figure 6 Microstructure analysis of LM12+10\% $\mathrm{SiC}$ 


\subsection{Microstructure analysis of Aluminum alloy of $\mathrm{LM} 12+15 \% \mathrm{SiC}$}

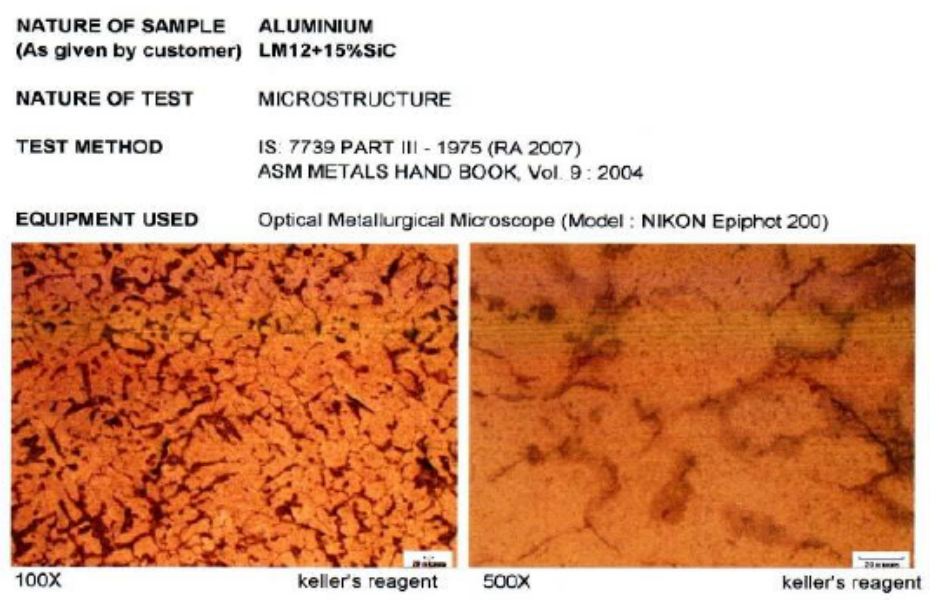

Figure 7 Microstructure analysis of LM12+15\% SiC

\subsection{Microstructure analysis of Aluminum alloy of LM12+20\%SiC}

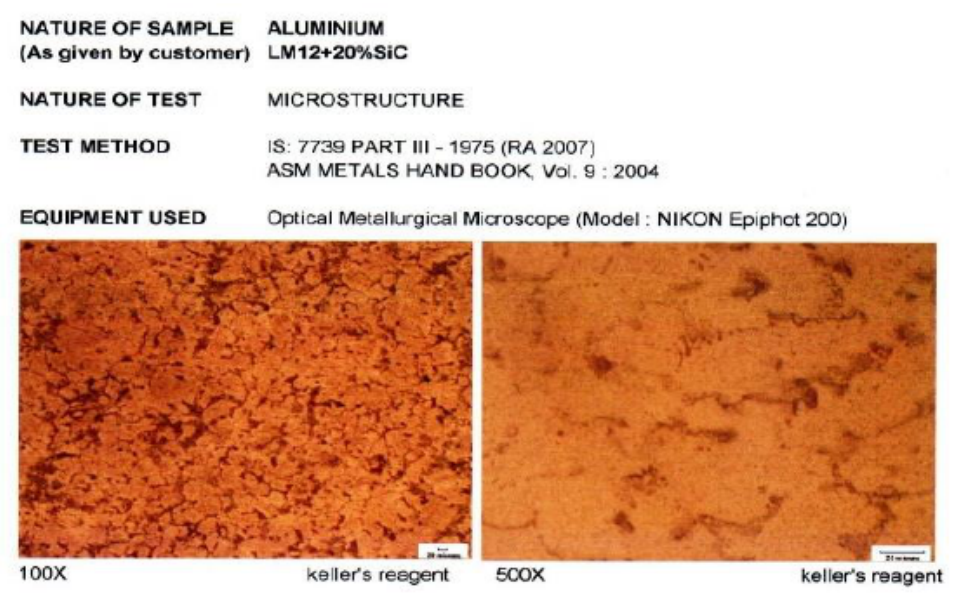

Figure 8 Microstructure analysis of LM12+20\% $\mathrm{SiC}$

Fig.5-8 displays the electron micrograph of the base metal LM12 and its composite at 0, 5, 10, 15 and $20 \%$ SiC. Base alloy LM12 (Fig.5) reveals Al matrix (light gray) with islands of silicon (dark gray). Composite of LM12 with 5\% SiC (Fig.6) 10\% SiC (Fig.6) depict a similar base metal microstructure interspersed with fine particles (light grey) of SiC. Composite with $15 \%$ reinforcement (Fig.7) reveals denser and also be with very fine particles (light grey) of SiC. Composite with 20\% reinforcement (Fig.8) reveals high denser.

\section{CONCLUSIONS}

Composite of aluminum alloy LM12 and silicon carbide was successfully fabricated by a stir casting route and tested. Microstructure of the composite revealed a fairly uniform distribution of silicon carbide in LM12 matrix.

Silicon carbide reinforcement enhanced the hardness of the composite. With increasing reinforcement content an increase in hardness was observed. Increase in hardness (BHN) could be attributed to dispersion hardening resulting from the reinforcement particle aggregate.

Following increase in hardness (BHN) an improvement in strength and reduction in percent elongation and reduction of area were noticed. 
The microstructural investigation reveal the uniform distribution of $\mathrm{SiC}$ particles in to $\mathrm{Al}$ matrix. It is very difficult to obtain the exact percentage of $\mathrm{SiC}$, but it has been successfully achieved by adopting suitable process parameters. By this process achieve the homogeneous and uniform distribution of reinforcement. The addition of silicon carbide particles to the matrix alloy improves the mechanical properties such as hardness and improves the material strength of molecules of the matrix alloy.

\section{REFERENCES}

[1] A.K.Kaw “ Mechanics of Composite Materials" Taylor and Francis Group, Press 2006) LLC(CRC

[2] Hasim, J., Looney, L., Hashmi, M. S. J.”Metal matrix composites production by the stir casting method", Journal of Materials Processing Technology(Elsevier 1999) Vol.9293,pp1-7.

[3] Vikram Singh and R.C. Prasad "Tensile and fracture behavior of Al 606-SiC metal matrixComposites"

[4] Sahin, Y "Preparation and some properties of $\mathrm{SiC}$ particle reinforced aluminium alloy composites" Materials and Design 24 ( Elsevier 2003),671-679.

[5] Davis, J.R (Ed.) "Properties and Selection, Nonferrous alloys and Special Purpose Materials", MetalsHandbook Vol 2 (ASM International1990),592-633.

[6] W. Zhou, Z. M. Xu "Casting of SiC Reinforced Metal Matrix Composites" Journal of Materials Processing Technology 63 (Elsevier 1997)358-363

[7] B Agarwal and D. Dixit "Fabrication of aluminium based composites by foundry techniques", Transaction of Japan Institute of Metals Vol 22 (8) (1981)93.

[8] M. Mares"Some issues on tailoring possibilities for mechanical Properties of particulate reinforced Metal matrix Composites" Journal of Optoelectronics and Adva nced Materials,Vol. 3(1) (2001),119- 124.

[9] W.Clyne "Metal Matrix Composites:Matrices and Processing”,Encyclopaedia ofMaterials: Science and Technology (Elsevier 2001).

[10] T.W.Clyne"Metal Matrix Composites: Matrices and Processing", Encyclopaedia of Materials: Science and Technology (Elsevier2001).

[11] T.W. Clyne and P.J. Withers. "An Introduction to Metal Matrix Composites" 1st Ed., Cambridge University Press, Cambridge, 1993. pp.1-10.

[12] D.M. Skibo, D.M. Schuster and L. Jolla. "Process for preparation of composite materials containing nonmetallic particles in a metallic matrix and composite materials "US Patent No. 4-786-467(1988)

[13] F. Khomamizadeh and A. Ghasemi "Evaluation of Quality Index of A-356 Aluminum Alloy by Microstructural Analysis, Scientia Iranica, Vol.11(4) (2004)386-391.

[14] Mohan Vanarotti, Shrishail P, B R.Sridhar, K.Venkateswarlu \& S A. Kori,"Study of Mechanical Properties \& Residual Stresses on Post Wear Samples of A356-SiC Metal Matrix Composites" Procedia Material Science, Vol 5 (Elsevier, 2014) 873-882. 
[15] George E Deiter “Mechanical Metallurgy" SI Metric Edition (McGraw-Hill1988)

[16] Sidney H Avner “ Introduction to Physical Metallurgy” (Tata McGraw Hill1997).

[17] N. Cayetano-Castro, H. J. Dorantes-Rosales, V. M. López- Hirata, J. J. CruzRivera,J.Moreno-Palmerin, and [18] J. L. González-Velázquez, "Coarsening kinetics of coherent precipitates in Fe-10\% Ni-15\% alloy," Revista de Metalurgia de Madrid, vol. 44 (2),(Elsevier 2008), pp. 162-169.

[18] K. Thornton, N. Akaiwa, andP. W. Voorhees, "Large-scale simulations of Ostwald ripening in elastically stressed solids: Development of microstructure" Acta Materialia, vol. 52 (5), (Elsevier 2004), pp.1365-1378

[19] M.Schober, C. Lerchbacher, E. Eidenberger, P. Staron, H. Clemens, andH.Leitner, "Precipitation behavior of intermetallic NiAl particles in Fe-6 at.\%Al-4at.\%Ni analyzed by SANS and 3DAP” Intermetallics, vol. 18 (8), (Elsevier 2010) pp. 1553-1559.

[20] N. Cayetano-Castro, M. L. Saucedo-Muñoz, H. J. Dorantes- Rosales, Jorge L. GonzalezVelazquez, J. D. Villegas-Cardenas, and V. M. Lopez-Hirata "Ostwald Ripening Process of Coherent $\beta \square$ Precipitates during Aging in Fe0.75Ni0.10 A 10.15 and Fe0.74 Ni0.10 A10.15Cr 0.01 Alloys" Advances in Materials Science and Engineering (HindawiPublishiCorporation,2015) Volume 2015, pp1-7 (22)ASM Metal Hand Book on Fractography, Vol.12 Ed. Mills, Kathleen, Davis, Joseph R (ASM International, 1987). 